\title{
A simplified model to evaluate the radiological impact of an accident with a nuclear reactor submerged at the sea
}

\author{
A.S. Paschoa ${ }^{1,3}$, C.A. de Moura ${ }^{2}$ and V.B. de Castro ${ }^{2}$ \\ ${ }^{1}$ Laboratório de Radioecologia e Mudanças Globais (LARAMG) \\ 2 Instituto de Matemática e Estatística (IME), Universidade do Estado do Rio de Janeiro \\ (UERJ), Rua São Francisco Xavier, 524. Maracanã, RJ 20550-013, Rio de Janeiro, Brazil \\ ${ }^{3}$ Instituto de Radioproteção e Dosimetria (IRD),Comissão Nacional de Energia Nuclear \\ (CNEN), Av. Salvador Allende s/n ${ }^{\circ}$, Recreio dos Bandeirantes, RJ 22780-160,
}

Rio de Janeiro, Brazil

\begin{abstract}
There are various scenarios dealing with releases of radionuclides in a water body, for example, accidents in nuclear power plants located in coastal areas, on margins of rivers or lakes. Meager attention has been given, however, to potential accidents with nuclear reactors submerged at sea. The latter type of accidents may occur with partial or total loss of the nuclear reactor core to the adjacent waters. In addition to initial instantaneous releases, one may estimate delayed sources based on rates of leaching or dissolving solid materials which are part of the core. Transport equations were used to estimate concentrations of radionuclides in water. Time dependent functions of concentrations of radionuclides in the aquatic food chain reflect the absorption and elimination processes in the flora and fauna. However, to avoid the multiparametric complexity which can be inserted in these processes, the model takes into proper consideration in a simplified way the transfer of radionuclides through trophic levels. The model avoids the need to analyze step-by-step the details of transfer factors used to determine radionuclide accumulation in fish, crustaceans, mollusks, and algae. This simplified model may help authorities in the case of an accident with a nuclear reactor submerged at sea.
\end{abstract}

\section{INTRODUCTION}

Merchant ships like the Savannah from the United States, the Otto Hahn from Germany, the Mutsu from Japan, and the icy-breaker Lenin from the former Soviet Union proved that the nuclear energy could be used as a reliable source of energy for maritime propulsion since 1960. By the end of last century, the United States Navy had commissioned almost 200 nuclear submarines from which two of them the Scorpion and the Thresher were lost at sea. On 12 August 2000 the nuclear submarine Kursk sank in the Barents with loss of all 118 persons aboard. It is known that nuclear reactors from some former Soviet Union submarines which were decommissioned lie at the bottom of the Kara Sea, though the radioactive releases are considered to be localized [1, 2]. In December 2007, the Arktika class ice-breaker with nuclear propulsion - 50 Years Victory - started trials for Arctic exploration. This fact suggests that the use of nuclear propulsion is far from over.

The current work describes a simplified model to assess the radiological impact of an accident with a nuclear reactor at sea. The basic elements considered for modeling accidents were the following: source terms; concentrations of radionuclides in the water; transport and diffusion of radionuclides in the sea water; accumulation of radionuclides in the aquatic food; and dose to humans from the ingestion of contaminated aquatic food. The model elements will be treated subsequently in separate sections of the paper.

\section{SOURCE TERMS}

The source terms considered in a postulated accident are usually based in hypotheses concerning the quantity of fission products and other radionuclides, like activation products, extant in the reactor core 
and cooling systems which can be released into a water body adjacent to the accident. There is not any particular mechanistic sequence to be considered in the accident scenarios used in this work. Neither aggravating nor mitigating circumstances which might occur during an accident with a nuclear reactor used in naval propulsion will be considered in the model. Nuclear missiles which might be onboard a nuclear submarine, or in another vessel will not be included as source terms.

Four source terms for scenarios were taken into consideration, though there are others that can be used in more detailed studies. Initial and delayed sources are considered in all cases. The main source term considered here consists of an initial one month long release fractions based on WASH 1400 [3], followed by two years of continuous leaching.

Table 1. Simplified source terms used in modeling nuclear accidents.

\begin{tabular}{|c|c|c|}
\hline $\begin{array}{l}\text { SOURCE TERM } \\
\text { IDENTIFICATION }\end{array}$ & $\begin{array}{l}\text { TEMPORAL STATUS OF THE } \\
\text { SOURCE TERM }\end{array}$ & COMMENTS \\
\hline \multirow[t]{2}{*}{$\mathbf{A}$} & Initial & $\begin{array}{c}1 \text { month - release fractions } \\
\text { based on WASH } 1400\end{array}$ \\
\hline & Delayed & Continuous leaching for two years \\
\hline \multirow[t]{2}{*}{ B } & Initial & $\begin{array}{c}\text { Same as A, but release fractions } \\
\text { based on fission products } \\
\text { vaporization at } 2.000^{\circ} \mathrm{K}\end{array}$ \\
\hline & Delayed & Same as A \\
\hline \multirow[t]{2}{*}{$\mathbf{C}$} & Initial & $\begin{array}{c}\text { Instantaneous release of } 1 \% \text { of core } \\
\text { inventory }\end{array}$ \\
\hline & Delayed & $\begin{array}{l}10 \% \text { release of core inventory at a } \\
\text { exposential rate at } 3 \text { month half life }\end{array}$ \\
\hline \multirow{2}{*}{ D (LOCA)* } & Initial & $0-24$ hours \\
\hline & Delayed & $0-30$ days \\
\hline
\end{tabular}

*LOCA means "loss-of-coolant-accident" (i. e., an accident with total or partial loss of the reactor cooling liquid).

Table 2. Volatility fraction $V_{i}$ for relevant elements i. Data taken from reference [3].

\begin{tabular}{|c|c|}
\hline VOLATILITY FRACTION V & CHEMICAL ELEMENTS \\
\hline 1 & $\mathrm{I}, \mathrm{Br}, \mathrm{Cs}, \mathrm{Rb}, \mathrm{Te}, \mathrm{Se}, \mathrm{Sb}, \mathrm{As}, \mathrm{In}, \mathrm{Sn}, \mathrm{Ge}$ \\
\hline 0,11 & $\mathrm{Sr}, \mathrm{Ba}, \mathrm{Ra}$ \\
\hline 0,08 & $\mathrm{Ru}, \mathrm{Mo}, \mathrm{Pd}, \mathrm{Rh}, \mathrm{Tc}, \mathrm{Ag}, \mathrm{Cd}$ \\
\hline 0,013 & $\mathrm{La}, \mathrm{Y}, \mathrm{Ce}, \mathrm{Nd}, \mathrm{Pr}, \mathrm{Pm}, \mathrm{Sm}, \mathrm{Eu}, \mathrm{Gd}, \mathrm{Tb}, \mathrm{Dy}, \mathrm{Ho}, \mathrm{Zr}$, \\
& $\mathrm{Nb}, \mathrm{Th}, \mathrm{Pa}, \mathrm{U}, \mathrm{Np}, \mathrm{Pu}, \mathrm{Am}, \mathrm{Cm}$ \\
\hline
\end{tabular}

The source term chosen for developing the current model coincides with case A in Table 1. As it occurs in each of the four cases, there are an initial and a delayed source terms implying in both cases releases to the adjacent water body.

The instantaneous release fraction of a radionuclide from the core inventory per unit power, in $\mathrm{Bq} \cdot \mathrm{kW}(\mathrm{th})^{-1}$ is denoted here as $\mathrm{Rp}_{\mathrm{i}}$. The quantity $\mathrm{Rp}_{\mathrm{i}}$ can be expressed as:

$$
\operatorname{Rp}_{\mathrm{i}}(0)=\frac{\mathrm{V}_{\mathrm{i}} \mathrm{A}_{\mathrm{i}}}{\mathrm{P}}
$$

where $V_{i}$ is the volatility fraction for the radionuclide $i, A_{i}$ is the activity of radionuclide $i$ in the core inventory at the time at the accident (in $\mathrm{Bq}$ ), and $\mathrm{P}$ is the thermal power (in $\mathrm{kW}(\mathrm{th})$ ) of the nuclear reactor used for ship or submarine propulsion.

The delayed source can be considered as composed of two parts. The first encompasses the value of the leach rate coefficient $F_{1}$ up to 30 days, while the second uses the value for the leach rate coefficient $\mathrm{F}_{2}$ from 1 month to 2 years. The time dependent release fraction $\mathrm{Rp}_{\mathrm{i}}(\mathrm{i})$ corresponding to the delayed 
source up to 2 years can be expressed as.

$$
\mathrm{Rp}_{\mathrm{i}}=\frac{\mathrm{A}_{\mathrm{i}}}{\mathrm{P}}\left(1-\mathrm{V}_{\mathrm{i}}\right) \mathrm{F}_{1} \mathrm{e}^{-\lambda_{1} \mathrm{t}}
$$

where typical values for $\mathrm{F}_{\mathrm{j}}$ are $\mathrm{F}_{1}=5 \times 10^{-5}$ and $\mathrm{F}_{2}=5 \times 10^{-6}$.

\section{CONCENTRATIONS OF RADIONUCLIDES IN THE WATER}

Whenever an accident with release of radionuclides occurs at sea a patch of radionuclides is formed with the center at the very site of the accident. The concentration $w_{i}(r, t)$ of a radionuclide $i$ in the water at a radial distante $r$ from the patch center and at a dilution time $t$ can be generally described by an equation such as:

$$
w_{i}(r, t)=f(t) e^{g(r t)}
$$

where $f(t)$ is the patch center peak concentration at a time $t$, and $g(r, t)$ is a spatial-time distribution function.

Using data available in the literature it was developed an empirical formulae which was consistent with equation (3). It was possible to evaluate the radionuclide concentration in water across the patch at a given time. The expression obtained is essentially a Gaussian spatial distribution, which can be expressed as [4]:

$$
w_{i}(r, t)=\frac{M_{i}}{2 \pi d \sigma_{r}(t)} e^{-\frac{r^{2}}{2 \sigma_{r}^{2}(t)}} e^{-\lambda_{i} t}
$$

where $M_{i}$ is the activity of radionuclíde $i(\mathrm{~Bq})$, released instantaneously, $d$ is the depth (meters) of the water column in which the radionuclide released is initially mixed, $r$ is the distance (meters) of the center of the plume, $\lambda_{i}$ is the decay constant of radionuclide $\mathrm{i}$ (in days ${ }^{-1}$ ), $t$ is the lasted time (days ${ }^{-1}$ ), and $\sigma_{\mathrm{r}}(t)$ is the time dependent standard deviation (meters).

After 30 days the concentration of ${ }^{131} \mathrm{I}$ decreases by three orders of magnitude, while ${ }^{90} \mathrm{Sr}$ and ${ }^{137} \mathrm{Cs}$ and concentration will take 100 days to decrease two orders of magnitude. The ${ }^{90} \mathrm{Sr}$ and ${ }^{137} \mathrm{Cs}$ concentrations continue to be significant even after 100 days, while the ${ }^{131}$ I concentration looses its importance within few weeks.

Figure 1 represents the curves of activity concentrations in water of ${ }^{90} \mathrm{Sr},{ }^{131} \mathrm{I}$ and ${ }^{137} \mathrm{Cs}$. The curves for ${ }^{90} \mathrm{Sr}$ and ${ }^{137} \mathrm{Cs}$ which appear in Figure 1 cannot be separated in the scale of the graph, but the curve

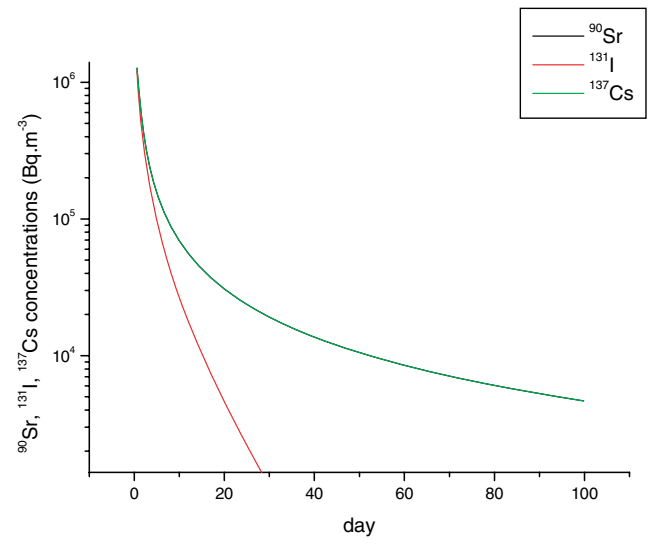

Figure 1. Graph curves representing the water concentration of ${ }^{90} \mathrm{Sr},{ }^{131} \mathrm{I}$ and ${ }^{137} \mathrm{Cs}$ as a function of time for, 0.6 day $<\mathrm{t}<100$ days, to illustrate the application of equation (4). 
for ${ }^{131}$ I appears clearly separated. The half lives of the three radionuclides represented in Figure 1 cover 3 orders of magnitude, as can be seen in Table 3.

Table 3. Half lives of selected radionuclides.

\begin{tabular}{|c|c|c|}
\hline RADIONUCLDE & HALF-LIFE (years) & DECAY CONSTANT $\boldsymbol{\lambda}\left(\mathbf{d a y}^{\mathbf{1}}\right)$ \\
\hline${ }^{90} \mathrm{Sr}$ & 29 & $6,5 \times 10^{-5}$ \\
\hline${ }^{131} \mathrm{I}$ & 0,02 & $9,5 \times 10^{-2}$ \\
\hline${ }^{137} \mathrm{Cs}$ & 30 & $6,3 \times 10^{-5}$ \\
\hline
\end{tabular}

Figure 2 shows the 2D and 3D representations of equation (4) for the case of ${ }^{90} \mathrm{Sr}$. In the $2 \mathrm{D}$ representation becomes clear the symmetry around the center of release, while in 3D the Gaussian characteristic of the distribution is evident.

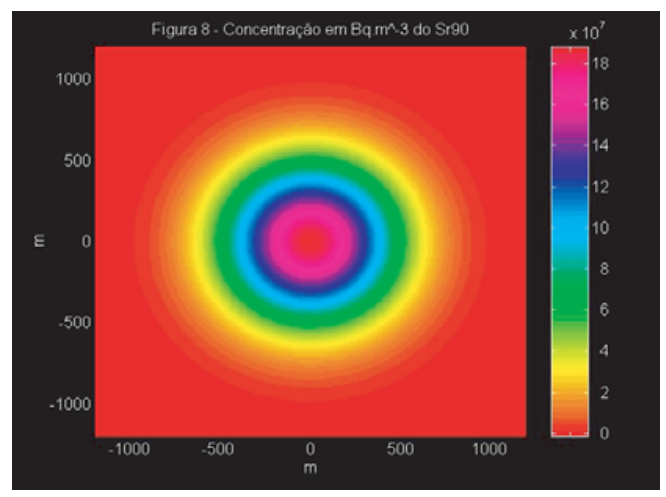

$2 \mathrm{D}$

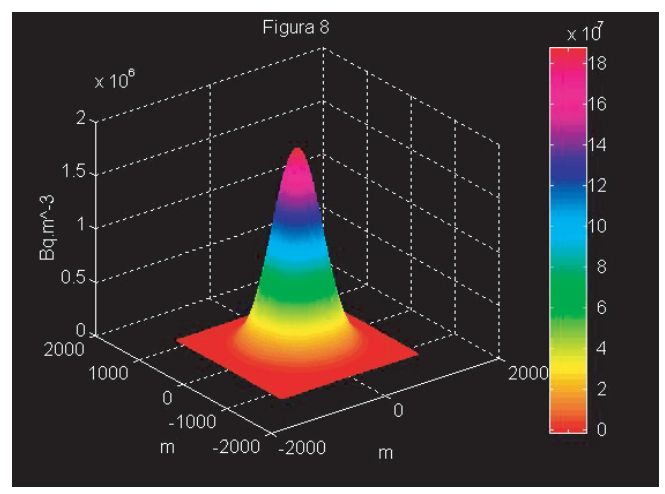

$3 \mathrm{D}$

Figure 2. Representations of equation (4) for the case of ${ }^{90} \mathrm{Sr}$ in $2 \mathrm{D}$ and $3 \mathrm{D}$.

It is worth mentioning here that time integration of equation (4) is important when the objective of the model is to estimate the radiation dose. The initial time for the integration (i.e., $t=0$ ), accepted as the lower limit of integration is, in general, considered as the instant immediately after the radioactive patch has reached a pre-determined minimum radius (i.e., the radius of the initial radioactive patch), which is much smaller than the total area related with the time integration of equation (4).

For continuous long term releases the concentration in water $w_{i}(x, y)$, of a radionuclíde $i$ at a point with coordinates $x, y$ can be described approximately by equation (5) [4]:

$$
w_{i}(x, y)=\frac{S_{i}}{2 d\left(\pi u x D_{y}\right)} e^{1 / 2} e^{-u y^{2} / 4 D_{y} x} e^{-\lambda_{i} x / u}
$$

where $w_{i}(x, y)$ is the activity concentration in water of radionuclide $i$ (in $\mathrm{Bq} \cdot \mathrm{m}^{-3}$ ), $S_{i}$ is the rate of release by the source of the activity of radionuclide $\mathrm{i}$ (in $\mathrm{Bq} \cdot \mathrm{d}^{-1}$ ), $d$ (in meters) is the depth of the water column at the point where the mixing starts, $u$ (in meter $\cdot$ day $^{-1}$ ) is the current speed along the longitudinal axis, $x$ (in meters) is the longitudinal distance parallel to the current, $D_{y}\left(\mathrm{in} \mathrm{m}^{2} \cdot \mathrm{day}^{-1}\right.$ ) is the lateral dispersion coefficient, $y$ (in meters) is the lateral distance normal to the current, and $\lambda_{i}$ (in day $^{-1}$ ) is the decay constant of the radionuclide $i$.

Equation (5) is based on the longitudinal advection with complete mixture at a selected depth of the water column. As one can observe in equation (5), the concentration $w_{i}(x, y)$ follows a Gaussian distribution in the lateral direction. The mixing process in depth waters is initiated at a $d=10 \mathrm{~m}$ depth for a typical thermo-cline. 


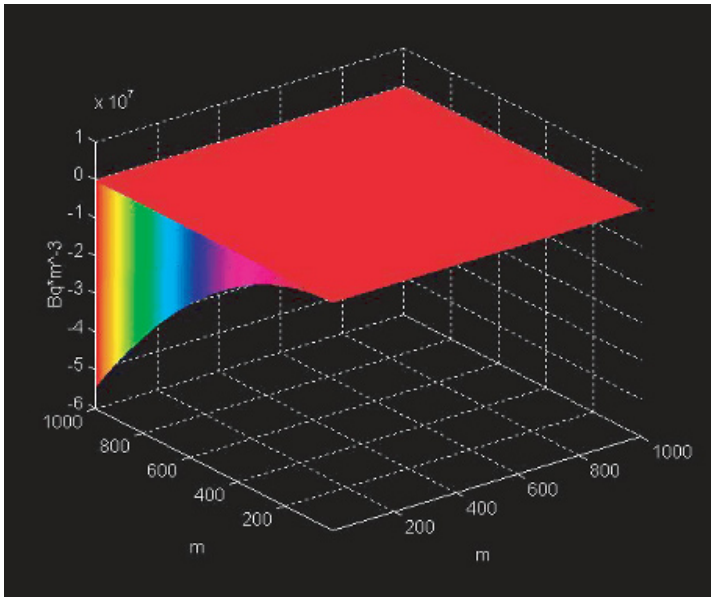

Figure 3. Representation of equation (5) at a continuous rate of release of $\mathrm{S}=4 \times 10^{4} \mathrm{MBq}^{90} \mathrm{Sr} \cdot \mathrm{day}^{-1}$.

A current speed $u_{x}=25 \mathrm{~cm} \cdot \mathrm{s}^{-1}\left(=2.16 \times 10^{4} \mathrm{~m} \cdot \mathrm{d}^{-1}\right)$ and a lateral dispersion coefficient $D_{y}=$ $5 \times 10^{2} \mathrm{~cm}^{2} \cdot \mathrm{s}^{-1}\left(=4,32 \times 10^{3} \mathrm{~m}^{2} \cdot \mathrm{d}^{-1}\right)$ are considered to be typical of the United States coastal region of the middle North Atlantic [5].

The effects of other $u_{x}$ and $D_{y}$ values of the concentrations $w_{i}(x, y)$ may be obtained by using multiplying factors, as presented in Figure 4.

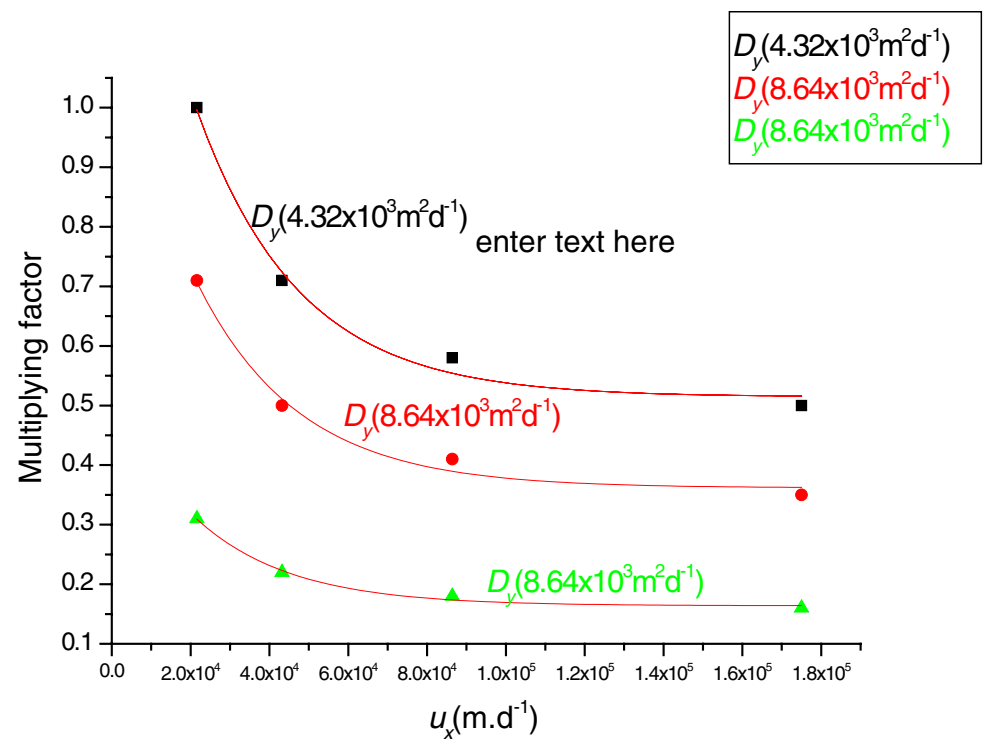

Figure 4. Illustrative graphs of multiplying factors to obtain concentrations $w_{i}(x, y)$ as a function of $u_{x}$ and $D_{y}$ values relative to $u_{x}=2.16 \times 10^{4} \mathrm{~m} \cdot \mathrm{d}^{-1}$, and $D_{y}=4,32 \times 10^{3} \mathrm{~m}^{2} \cdot \mathrm{d}^{-1}$. The curves correspond to three values of $D_{y}$ as shown in the upper right side box.

\section{RADIONUCLIDE ACCUMULATION IN AQUATIC FOOD}

The experience accumulated with pathway analysis of routine releases of radionuclides from nuclear power plants indicates that the radionuclide concentrations in edible aquatic food can be estimated 
through the knowledge of the radionuclide concentrations in the surrounding water by means of concentration factors $\left(C f_{t}\right)$.

Once one is aware of the limitations of a mathematical model, the elimination of an aquatic food can be modeled by means of an exponential function, such as:

$$
\frac{d F_{f i}}{d t}=C F_{f i} \lambda_{f e i} w_{i}(t)-F_{f i} \lambda_{f e i}
$$

where $F_{f i}$ is the concentration (in $\mathrm{Bq} \cdot \mathrm{kg}^{-1}$ ) of na radionuclide $i$ in the aquatic food $f$ (which can be fish, crustacean, mollusc, or algae), $w_{i}(t)$ is the time dependent ( $t$ in days) concentration (in $\mathrm{Bq} \cdot \mathrm{m}^{-3}$ ) of radionuclide $i, \lambda_{f e i}$ is the decay constant $\left(\right.$ in day ${ }^{-1}$ ) for the elimination of radionuclide $i$, and $C F_{f i}$ is the concentration factor of an aquatic food $f$.

$C F_{f i}$ is defined as:

$$
C F_{f i}=\frac{\text { concentration of radionuclide } i \text { in aquatic food } f\left(\mathrm{~Bq} \cdot \mathrm{kg}^{-1}\right)}{\text { concentration of } i \text { in water }\left(\mathrm{Bq} \cdot \mathrm{m}^{-3}\right)}
$$

The effective decay constant $\lambda_{f e i}$ is defined as

$$
\lambda_{f e i}=\lambda_{i}-\lambda_{f b i}
$$

where $\lambda_{i}$ is the radiological decay constant of radionuclide $i$ and $\lambda_{f b i}$ is the biological decay constant of the same radionuclide.

Here is worth to keep in mind that it is known for a long time that laboratory experiments had shown the variation of $C F_{f i}$ with the concentration of the radionuclide in the surrounding water, with the accumulation and distribution of the same radionuclide in the organism (through adsorption or an equivalent mechanism), as well as the accumulation of the radionuclide in environment compartments nearby [6].

Moreover, dose estimates for human beings using food chain pathways take into consideration only concentration factors (or bio-accumulation) for the edible parts of aquatic organisms. The factors for bio-accumulation for the whole body of an organism may differ considerably from those applicable to muscle and other tissues. For example, the concentration of ${ }^{137} \mathrm{Cs}$ does not vary much for different organs of a fish, thus the bio-accumulation factor for this radionuclide can be equally applied to the whole fish, or for the edible soft tissue [7]. On the other hand, ${ }^{226} \mathrm{Ra},{ }^{238} \mathrm{U}$ and ${ }^{239} \mathrm{Pu}$ are bone seekers, as a consequence fish bones contribute much more for the overall concentration of these radionuclides in fish than the concentrations in soft tissue [8].

There are a large number of reports published in the open literature concerning $C f_{f} s$. Typical values of $C F_{f}$ for fish range from 0.5 to $3.0 \times 10^{4}$. There is available also a list of $C f_{f} s$ for fish, mollusks, crustacean and seaweed.

It is also worth remembering, however, that calculations of time dependent concentrations of radioactivity in aquatic food following an accidental instantaneous release should reflect, as accurately as possible, the result of intake and elimination processes. The details of such processes are quite complex, and many parameters involved are dependent on environmental factors such as location, season, temperature and salinity. Thus, a generic model for calculating time-dependent concentrations of radionuclides in aquatic food can not be applied to any specific location concerning an accident, without a high degree of uncertainty.

Dose to non-human biota will not be examined here. However, it is important to mention that radionuclide accumulation in aquatic organisms may have dosimetric implications for these organisms with radioecological implications, mostly in connection with alpha radiation doses to eggs and embryos, or to plankton (Woodhead, 1979; Paschoa et al., 1981). 


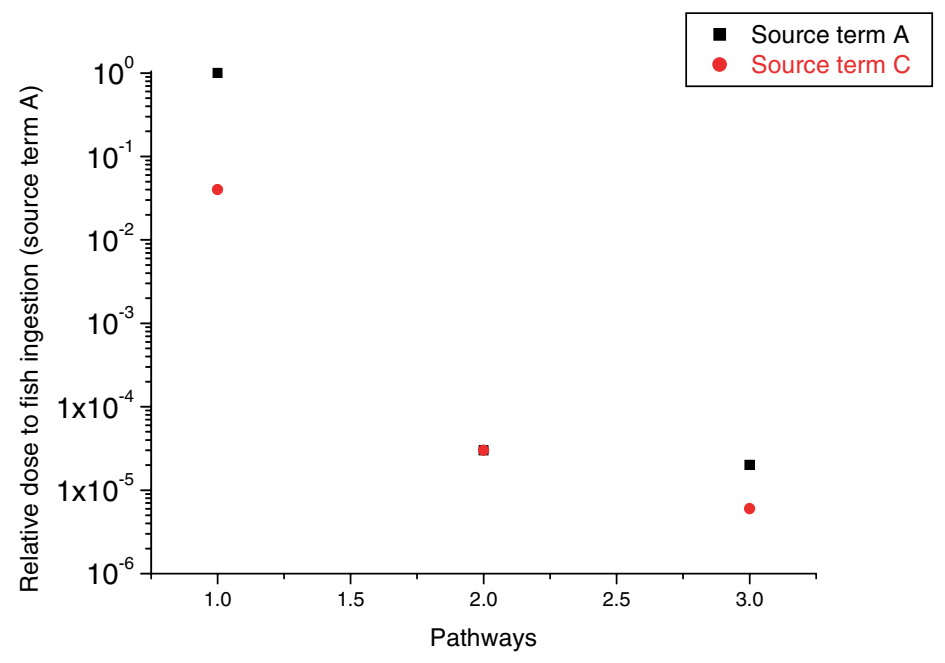

Figure 5. Comparison of doses estimates for fish ingestion (1), exposure to sediments (2), and swimming (3) for two selected source terms, A and C.

\section{DOSE TO HUMANS}

The details of dose calculations will not be presented here. However, for the sake of comparison, Figure 5 shows the relative importance of fish consumption, as far as dose estimates are concerned, to both external exposures - i.e., standing on contaminated sediments and swimming in contaminated water. In Figure 5, all data on estimated doses are normalized to internal exposure due to aquatic food (fish) ingestion (1). As it is described in Table 1, source term A means initial releases lasting one month, and retarded two years, while $\mathrm{C}$ means $1 \%$ of the core inventory is released instantaneously, and $10 \%$ at an exponential decay rate for three months. The concentrations for instantaneous and continuous models are superimposed. The data presented in Table 1 are normalized to internal exposure due to aquatic food (fish) ingestion. The contribution of airborne releases of radionuclides to the liquid pathway via rainfall or fallout was considered to be negligible, as compared with the direct releases of radionuclides to the liquid pathway. Therefore, additional doses from airborne releases were not considered in this dose evaluation.

\section{CONCLUSIONS}

A simplified mathematical model was developed to evaluate the time and spatial distribution of concentrations of radionuclides released into a water body due to a nuclear accident at sea. The time dependent concentrations for ${ }^{90} \mathrm{Sr}$ and ${ }^{137} \mathrm{Cs}$ behave similarly as expected. However, the dose estimates reflect the fact that ${ }^{137} \mathrm{Cs}$ accumulates in soft tissues of fish, while ${ }^{90} \mathrm{Sr}$ is a bone seeker. Detailed dose calculations were not presented here, but a comparison of the doses from swimming and direct exposure to sediments relative to fish ingestion was presented. The model can be refined to include more detailed calculations with site specific parameters.

\section{References}

[1] Salbu, B., A.I. Nikitin, P. Strand, G.C. Christensen, V.B. Chumichev, B. Lind, H. Fjelldal, T.D.S. Bergan, A.L. Rudjord, M. Sickel, N.K. Valetova and L. Foyn, Radioactive contamination from dumped nuclear waste in the Kara Sea - results from the joint Russian-Norwegian expeditions in 1992-1994, The Science of the Total Environment, 202 (1997) pp. 185-198. 
[2] Warden J.M., N.M. Lynn, M. Mount, Y. Sivintsev, S.J. Timms, E. Yefimov, K. Gussgard, R.S. Dyer and K.L. Sjoeblom, Potential radionuclide release rates from marine reactors dumped in the Kara Sea, The Science of the Total Environment, 202 (1997) pp. 225-236.

[3] WASH 1400, Reactor Safety Study, United States Regulatory Commission, October 1975.

[4] Okubo, A., Deep Sea Res., 18 (1971).

[5] Miyake, Y. and Saruhashi K. (1958) J. Mar. Res., 17, pp. 383.

[6] Paschoa, A.S. and Amaral, E.C.S. (1991) Transfer and Concentration Factors in Laboratory and Environmental Conditions, A.S. In High Levels of Natural Radiation, Ramsar, M. Sohrahi, J.U. Ahmed and S.A. Durani, Eds. (International Atomic Energy Agency, Vienna, 1991) pp. 125-133.

[7] Nelson, D.J. (1967) "Cesium, ${ }^{137} \mathrm{Cs}$, and potassium concentrated in White Crappie and other Clinch River fish," in Second National Symposium on Radioecology (Nelson, D.J. and Evans, F.C., eds.) Report No. Conf-670503 (National Technical Information Service, Springfield, Virginia) 240.

[8] National Council on Radiation Protection and Measurements, NCRP (1984) Radiological Assessment: Predicting the Transport, Bioaccumulation, and Uptake by Man of Radionuclides Released to the Environment, NCRP Report No. 76, 300 pp.

[9] Woodhead, D.S. (1973) Levels of radioactivity in the marine environment and the dose commitment to marine organisms, International Sympsoium on the Radioactive Contamination of the Marine Environment, Seattle, 10-14 July 1972 (International Atomic Energy Agency, Vienna, 1973 - IAEA-SM-158/31) pp. 499-525.

[10] Paschoa, A.S., Baptista, G.B., Wrenn, M.E. and Eisenbud E. (1981) Dosimetry of Natural and Man-Made Alpha Emitters in Plankton, International Symposium on the Impacts of Radionuclide Releases into the Marine Environment, Vienna, 6-10 October 1980 (International Atomic Energy Agency, 1981 - IAEA-SM-248/140) pp. 695-716. 